\title{
O DIREITO ANTITRUSTE BRASILEIRO E A REPRESSÃO À CONCORRÊNCIA ILÍCITA: FORMAÇÃO DE CARTÉIS E ACORDOS NA LEI 12.529/2011
}

Isadora Santos, João Paulo Angelo Vasconcelos

Universidade do Oeste Paulista - UNOESTE, Presidente Prudente, SP. E-mail: isadora s@outlook.com

\section{RESUMO}

O presente artigo tem por escopo estudar o Direito da Concorrência e estabelecer sua concepção na e para a contemporaneidade, com base na qual será analisado o Sistema Brasileiro de Defesa da Concorrência. Dada a sua concepção analítica e crítica, o trabalho é executado conforme o método dedutivo, sem olvidar do recurso a abordagem hermenêutico-dialética. Analisados alguns instrumentos considerados adequados a repressão à cartelização, o estudo aclara as nuances que a permeiam sob a ótica da Lei de Defesa da Concorrência. Compreendido, na contemporaneidade, como instrumento para a implementação de políticas públicas destinadas a tutela da livre concorrência, a repressão ao abuso do poder econômico e a persecução de ilícitos anticoncorrenciais, o Direito Antitruste brasileiro estruturou um sistema de proteção dúplice da concorrência - controle das estruturas e das condutas - e, autorizando ao CADE a celebração de acordos com agentes econômicos infratores, assegurou o uso de instrumentos efetivos para a comprovação das práticas ilícitas, a repressão-punição e a prevenção, notadamente quanto aos cartéis.

Palavras-chave: direito da concorrência; formação de cartéis; repressão; CADE; acordos; leniência.

\section{BRAZILIAN ANTITRUST LAW AND REPRESSION OF ILLICIT COMPETITION: FORMATION OF CARTELS AND AGREEMENTS IN LAW 12.529/2011}

\begin{abstract}
The scope of this article is to study Competition Law and establish its conception in and for contemporaneity, based on which the Brazilian System for the Defense of Competition will be analyzed. Given its analytical and critical conception, the work is carried out according to the deductive method, without forgetting the use of the hermeneutic-dialectic approach. After analyzing some instruments considered adequate to repress cartelization, the study clarifies the nuances that permeate it from the perspective of the Competition Defense Law. Understood, in contemporary times, as an instrument for the implementation of public policies aimed at safeguarding free competition, the repression of the abuse of economic power and the pursuit of anti-competitive offenses, the Brazilian Antitrust Law structured a system of dual protection of competition - control of structures and conduct - and, by authorizing CADE to enter into agreements with infringing economic agents, it ensured the use of effective instruments for proving illegal practices, repression- punishment and prevention, especially with regard to cartels. Keywords: competition law; formation of cartels; repression; CADE; agréments; leniency.
\end{abstract}




\section{INTRODUÇÃO}

A evolução da relação Estado-economia fez surgir o Direito Econômico, que experimentou uma divisão interna e deu origem ao Direito da Concorrência ou Direito Antitruste. No Brasil, tradicionalmente as Constituições estabelecem o dever de repressão ao abuso do poder econômico, o que demanda a atuação efetiva de órgãos estatais. E com o advento da lei antitruste nacional foi instituído um Sistema Brasileiro de Defesa da Concorrência (SBDC), protagonizado pelo Conselho Administrativo de Defesa Econômica (CADE).

Este trabalho tem por objetivo estudar a evolução histórica do Direito da Concorrência e buscar por uma definição contemporânea e constitucionalizada que justifique a implementação de políticas públicas destinadas a atuação preventiva e repressiva mais eficiente e efetiva no âmbito do SBDC. Especificamente, visa a verificar a eficiência e utilidade de mecanismos legais na repressão à concorrência ilícita.

Para tanto, ao delinear sobre o SBDC e tomar como pano de fundo o Direito da Concorrência, serão trabalhados os mecanismos legislativos de que dispõe a Autoridade antitruste brasileira para descortinar os movimentos estruturais das empresas no mercado e reconhecer se essas condutas impactarão de forma expressiva a livre concorrência, afetando negativamente as relações comerciais tuteladas pela Constituição Federal e leis infraconstitucionais.

Assim, para além da relevante fixação de entendimento sobre a extensão da tutela da concorrência, olhar-se-á de modo especial em direção a formação e a repressão à cartelização infração criminal e extrapenal contra a ordem econômica, antigo e recorrente que afeta as relações consumeristas -, notadamente a partir da análise do programa de leniência antitruste e do termo de cessação da conduta anticompetitiva, instrumentos consensuais de inegável importância científica e prática.

Feitas tais reflexões, o estudo trará à baila dois institutos próprios da esfera concorrencial brasileira, especificamente o Acordo de Leniência e o Termo de Compromisso de Cessação, que, por intermédio da Autoridade Pública do CADE, criam ambiente favorável ao combate à cartelização.

A relevância do tema - e do trabalho também se mede pela necessidade atual de se conhecer melhor o Direito Concorrencial e o Sistema Brasileiro da Concorrência, destinados a tutelar valores constitucionais (livre concorrência, livre iniciativa e o interesse do consumidor) e que dispõem de ferramentas tidas como pontos nodais para que a persecução de ilícitos ocorra de forma efetiva.

\section{METODOLOGIA}

Este trabalho analítico e de revisão bibliográfica se realiza conforme o método dedutivo, emanado de uma generalização para uma questão mais particularizada, sobretudo no que diz respeito a análise da evolução dos institutos estudados segundo a ordem jurídica constitucional e infraconstitucional.

Para Gil (2008), este meio de pesquisa parte de princípios reconhecidos como verdadeiros e indiscutíveis, possibilitando chegar a conclusões em virtude unicamente de sua lógica. É o segmento proposto pelos racionalistas, segundo os quais só a razão é capaz de levar ao conhecimento verdadeiro, que decorre de princípios a priori evidentes e irrecusáveis.

A abordagem define-se pela hermenêutica-dialética. A hermenêutica pode ser considerada como uma técnica que compreende textos, em sentido amplo: biografia, livro, artigo, narrativa, documento, pareceres, legislações, jurisprudências, teses e dissertações. Por sua vez, a abordagem dialética procura nos fatos os núcleos obscuros e contraditórios, para realizar críticas em relação aos mesmos. $O$ pensamento dialético compreende que a análise dos significados deve ser realizada, considerando as práticas sociais e ressaltando o condicionamento histórico das falas (MINAYO, 2010).

Observada a referida metodologia e tendo por base o Direito Concorrencial e a sua finalidade instrumental decorrente da historicidade da relação Estado-economia, reflete-se a respeito dos acordos previstos na lei antitruste brasileira como meio para a efetiva repressão à concorrência ilícita.

\section{DIREITO DA CONCORRÊNCIA}

O direito da concorrência consiste-se, objetivamente, em linhas gerais, num conjunto de normas e princípios concebidos para assegurar a liberdade econômica no mercado, sustentandoo enquanto ambiente competitivo, buscando mantê-lo a salvo de condutas anticoncorrenciais praticadas por agentes econômicos, mas, 
reprimindo-as em diferentes esferas quando atentatórias da livre iniciativa e da livre concorrência.

Hodiernamente, num sentido consentâneo ao papel conferido ao Estado na seara econômica, a disciplina jurídica da concorrência pode ser concebida como sendo "um instrumento de que lança mão o Estado para dar concreção à determinada política pública" (FORGIONI, 2016), definição condizente com o conteúdo do direito econômico segundo Fábio Konder Comparato (1978): "o conjunto de técnicas jurídicas de que lança mão o Estado contemporâneo na realização de sua política econômica, que constitui a disciplina normativa da ação estatal sobre as estruturas do sistema econômico, seja ele centralizado ou descentralizado".

Tal compreensão acerca do papel estatal frente ao mercado e seus atores, sobretudo em contextos econômicos liberais, evoluiu historicamente a partir do século XIX. Antes, desde a antiguidade grega ${ }^{1}$, passando pela romana $^{2}$, pela Idade Média ${ }^{3}$ e no mercantilismo ${ }^{4}$, as regras para o comportamento dos agentes econômicos (sobretudo, mercadores e comerciantes) tinham por finalidade atender a razões práticas, eliminar distorções pontuais, ou mesmo viabilizar a constituição de monopólios, não se tratando de uma regulação generalista e destinada a todos (FORGIONI, 2016).

\footnotetext{
${ }^{1}$ A história grega é formada por 5 períodos (divisões aproximadas, iniciando no Período Pré-Homérico (2000-1100 a.C.) e terminado no Período Helenístico (338-136 a.C.), com declínio da civilização grega, dominada pelos macedônicos. As referências históricas ao "antitruste" na antiguidade grega concentram-se a partir do período clássico, que perdurou até a queda do Império romano do ocidente no século $V$ d.C.

${ }^{2}$ A civilização romana se estendeu desde a fundação da cidade, 753 a.C, até o fim do Império Romano do Ocidente, em 476 d.C. A história política da Roma Antiga divide-se em três fases: Monarquia Romana: período que durou até 509 a.C., quando ocorreu a expulsão dos etruscos; República Romana: até o ano 27 a.C.; Império Romano: que terminou em 476 d.C.

${ }^{3}$ A Idade Média é o nome do período da história localizado entre os anos 476 e 1453, sendo dividida pelos historiadores em duas fases, a Alta Idade Média, séculos $V$ ao $X$ (desagregação do Império Romano e formação do feudalismo) e Baixa Idade Média, séculos XI ao XV (auge do feudalismo e início das transformações oriundas do renascimento urbano e comercial europeu).

${ }^{4}$ Momento em que se identifica o crescimento do poder econômico do Estado. Surge o conceito de monopólios legais - concessão pelo soberano - impulsionando as navegações marítimas. Daí falar-se num modelo intervencionista surgido em razão da expansão marítima comercial do século XVI, em cujo processo econômico identificou-se nova classe social (a burguesia, composta por comerciantes e artesãos) e que observava um conjunto de princípios da política econômica do capitalismo comercial que orientaram as monarquias absolutistas.
}

Fato histórico interessante e que ilustra a indiferença do Estado à regulação do mercado diz respeito à figura das corporações de ofício ${ }^{5}$, cuja necessidade de organização levou a união espontânea de comerciantes em busca de proteção por interesse comum e a uma forma de cartelização de um ou mais setores da economia da época, dando azo a criação de ajuste (normativo) de "não concorrência", o que, grosso modo, significa a fixação de regras sobre o comportamento dos agentes econômicos.

O liberalismo econômico clássico do final do século XVIII apregoava a não-intervenção do Estado na economia. A ideia atribuída a Adam Smith reformulou a concepção de mercado (de meio da realização do interesse individual para ambiente no qual os agentes buscavam o interesse geral, a satisfação de todos, o bemestar). Em sua obra de $1776^{6}$, o filósofo e economista britânico referiu que o intervencionismo estatal na economia se apresentava como sendo um óbice ao progresso econômico, pois haveria uma "mão invisível" que autorregularia o mercado - uma arena na qual os agentes econômicos fazem trocas e também competem entre si (FORGIONI, 2016).

Segundo a orientação econômica liberal, a concorrência passa a ser a solução conciliatória entre liberdade econômica individual e interesse público, na medida em que a preservação da competição atenderia, de um lado, ao interesse público relativo à prática de preços inferiores aos do mercado monopolizado, a um maior nível de atividade econômica e a melhora na qualidade dos produtos, e de outro, a liberdade de dos agentes econômicos, resultando no combate aos monopólios e no bem-estar (FORGIONI, 2016).

A livre atuação levou à concentração de capitais - formação de oligopólios e monopólios -, movimento natural no contexto rigidamente concorrencial (no qual o empreendedor é conduzido a procurar a melhor combinação de fatores de produção) e orquestrado ao aumento dos lucros. Reflexamente, acarretou a elevação de preços e condições desfavoráveis de trabalho, "distorções (que) geraram insatisfação popular e

\footnotetext{
${ }^{5}$ Dos séculos XII a XVIII, até o advento do Código Comercial Francês, 1807, ou até 1791 (quando, em França, a Lei Chapelier passa a proibir as corporações), a ausência de um direito comercial estatal permitiu que comerciantes se associassem em corporações, instituições que produziam as suas próprias normas, fiscalizavam a sua execução e cumprimento e resolviam internamente os conflitos de interesse havidos entre os seus membros (função jurisdicional que, depois, se estendeu a não comerciantes). (FORGIONI, 2009)

${ }^{6} \mathrm{O}$ texto se refere a "Uma Investigação sobre a Natureza e as Causas da Riqueza das Nações" (A riqueza das nações).
} 
culminaram com a regulamentação da concorrência entre os agentes econômicos, dentre outras medidas destinadas à atenuação do problema." (FORGIONI, 2016). João Bosco Leopoldino da Fonseca (2017) também se dedica ao tema e, subsidiado nas lições de Gérard Farjat, credita o surgimento do Direito Econômico à concentração capitalista, um fenômeno que deu etmo ao poder econômico privado e o estimulou a rivalizar com o poder estatal.

A superação do absenteísmo estatal levou à multiplicação de normas legais destinadas a viabilizar e regular a intervenção estatal na economia. Trata-se do Direito Econômico - ramo do Direito Público - que traz a disciplina jurídica da atividade econômica e a sua regulação direta ou indireta. Dessa relação que se estabelece entre Estado e economia, o Direito da Concorrência se instala como uma divisão interna do Direito Econômico, porém, não se confundindo com o Direito Regulatório ${ }^{7}$.

A despeito da produção de algumas leis no início do século XXIX ${ }^{8}$, é assente na doutrina que o primeiro diploma legal antitruste coincide com o Sherman Act, de 1890, editado nos Estados Unidos num contexto de desenvolvimento econômico e no qual verificada a concorrência predatória e a falta de competividade ${ }^{9}$.

\footnotetext{
${ }^{7}$ Calixto Salomão Filho (2008) distingue ambos sub-ramos do Direito Econômico. Para o autor, enquanto que na regulação a intervenção estatal é ativa (cria utilidades públicas, faz dirigismo - ex.: serviços públicos), a disciplina jurídica da concorrência revela atuação passiva (limita-se à fiscalização e controle dos atos de concentração; controla as estruturas do mercado e sanciona as condutas anticoncorrenciais - infração da ordem econômica e concorrência desleal).

${ }^{8}$ Em 1810, França, lei sobre estabelecimentos insalubres; 1814, Inglaterra, lei sobre o emprego das crianças; 1819, Inglaterra, lei sobre o trabalho das crianças nas lavouras de algodão; 1905, Lei do Estado de NY sobre limitação da jornada de trabalho a 60 horas semanais (julgada inconstitucional pela Suprema Corte - o cidadão tem o direito de vender o trabalho livremente).

${ }^{9} \mathrm{Na}$ época, surgiam as primeiras "corporations" para atender às necessidades da indústria, verificando-se, ainda, a concorrência predatória entre as ferrovias, levando à formação de associações pools ou cartéis -, prática que se estendeu a outros setores da economia. Institui-se o "trust", por meio do qual os empreendedores transferiam a um "trustee" os poderes inerentes as suas ações (recebia um "trust certificate") e estes se em carregavam de administrar, de forma centralizada, os negócios dos agentes que atuavam num mesmo mercado, gestão que, em vez de impulsionar a competição, impedia que a concorrência se estabelecesse entre eles, gerando concentração do poder nas mãos dos "trustee". Outros setores, eletricidade e indústria, também se organizaram na década de 1880 sob a forma trustes. A prática gerou discussões e alguns setores se colocaram contra a concentração do poder econômico (preços de monopólio, sujeição, corrupção de agentes públicos), culminando com a realização de campanha publicitária contra os "trutees". O posicionamento da população contra esse sistema, em 1887, orientou a campanha para a eleição presidencial estadunidense de 1888, vencida por Harisson Ford. Em
}

A imposição de normas econômicas - e de antitruste - recrudesce ante os acontecimentos verificados entre a metade do século XIX e o início do XX (primeiro pós-guerra e a crise de 1929, principalmente), conduzindo à mutação do seu papel no domínio econômico e sedimentando o desenvolvimento de um ordenamento jurídico próprio de intervenção na economia (BAGNOLI, 2017).

No ponto, ainda cumpre deixar registrado o surgimento de uma reação à compreensão, utilidade e eficiência do Direito Econômico: a Análise Econômica do Direito (AED), que pode ser definida como a aplicação da teoria econômica e de seus métodos no exame do direito - da formação (debate legislativo) à aplicação (debate judicial) - e das instituições jurídicas. Método de abordagem que é, a AED toma como ponto de partida que a Economia é útil para a análise e aplicação do Direito, na medida em que se as normas jurídicas são avaliadas segundo o grau de facilitação do uso de recursos escassos, na verdade está-se avaliando algo que terá efeito em toda a sociedade (por exemplo, a maximização dos resultados num ambiente de escassez).

No início (décadas de 1940/1950) restrita aos Direitos Comercial e Concorrencial, a AED da Escola de Chicago, de 1960/1970, estende-se a outros âmbitos do Direito não estritamente relacionados com a economia (regras contratuais, de responsabilidade civil e de Direito Penal e Processual).

No Brasil, desde a Constituição de 1934 denota-se a orientação a respeito da existência de uma ordem econômica, incialmente sob a bandeira da liberdade econômica, conquanto condicionada à existência digna e os princípios de justiça social. Capítulo à parte na história do direito constitucional brasileiro, a Constituição de 1937 intensificou a presença do Estado na atividade econômica, prevendo expressamente a "intervenção do Estado do domínio econômico" e o fomento a economia popular. Sob os auspícios desta Carta, promulgaram-se normas sobre antitruste, criou-se a Comissão Administrativa de

discussão desde 1888, o projeto de autoria do Senador John Sherman foi aprovado o Sherman Act. Focado na atividade dos trustes, o teor foi criticado por agentes econômicos por conta da falta de regulação da concentração econômica. Considerada insuficiente, esta lei foi aperfeiçoada por meio do Clayton Act, 1914 (tipifica e condena algumas práticas restritivas da concorrência venda casada, aquisição de controle de companhias), no mesmo ano tendo sido criada a Federal Trade Commision (FONSECA, 2017). No mesmo sentido: FORGIONI, 2016; e FRAZÃO, 2017. 
Defesa Econômica (CADE) e os crimes contra a economia popular passaram a ser considerados crimes por abuso de poder econômico, expressão depois adotada na Constituição Federal de 1946.

Com base na Constituição de 1946, expressa quanto a normas voltadas à repressão do abuso do poder econômico, da eliminação da concorrência e do aumento arbitrário dos lucros, foi editada (com atraso) a Lei n. 4.137/1962, considerada a primeira lei antitruste brasileira propriamente dita, que "criou" o CADE Conselho Administrativo de Defesa Econômica. No mais, o comando de repressão ao abuso do poder econômico, caracterizado pelo domínio dos mercados, a eliminação da concorrência e o aumento arbitrário dos lucros, manteve-se na Constituição de 1967.

A Carta da República em vigor traz normas importantíssimas a respeito do tema, dispondo sobre os princípios gerais da atividade econômica (livre concorrência, inclusive) e impondo a criação de lei que reprima o abuso do poder econômico que vise à dominação dos mercados, à eliminação da concorrência e ao aumento arbitrário dos lucros. E foi por conta dessa determinação do legislador constituinte que editadas as Leis no 8.884/94 (sistematizou a matéria antitruste, transformou o CADE em autarquia e implementou o Sistema Brasileiro de Defesa da Concorrência (SBDC) e a atual Lei Antitruste brasileira, a de no $12.529 / 2001$, por meio da qual reestruturado o SBDC e promovidas outras modificações.

A constitucionalização do Direito da Concorrência não é um fenômeno tipicamente local, nacional, porém, se impõe enquanto paradigma par a correta produção, interpretação e aplicação do ordenamento jurídico pátrio.

Ora, a partir da Constituição Econômica brasileira a concorrência constitui-se num meio para alcance de outro bem maior, "assegurar a todos existência digna". Daí dizer-se que os princípios da livre iniciativa e da livre concorrência são instrumentos da promoção da dignidade humana e que o Direito da Concorrência é "técnica de que lança mão o Estado contemporâneo para implementação de políticas públicas, mediante a repressão ao abuso do poder econômico e a tutela da livreconcorrência" (FORGIONI, 2016).

\section{SISTEMA BRASILEIRO DE DEFESA DA CONCORRÊNCIA}

Para bem implantar políticas públicas que atendam a disciplina jurídica da concorrência ou mesmo para assegurar a sua execução, a Lei 12.529/2011 (BRASIL, 2011) redimensionou o funcionamento do Sistema Brasileiro de Defesa da Concorrência, que é composto por dois órgãos: o Conselho Administrativo de Defesa Econômica (CADE) e a Secretaria de Acompanhamento Econômico (SAE).

A SAE foi extinta em 2018, passando as suas competências a serem exercidas pela Secretaria de Acompanhamento Fiscal, Energia e Loteria (SEFEL) e pela Secretaria de Promoção da Produtividade e Advocacia da Concorrência (SEPRAC), ambas hoje vinculadas ao Ministério da Economia, conforme dispõe o Decreto 9.745/2019 (BRASIL, 2019).

Por sua relevância, notadamente quanto a repressão administrativa da prática anticoncorrencial, analisa-se brevemente o CADE, autarquia federal composto de três órgãos: o Tribunal Administrativo de Defesa Econômica (TADE), a Superintendência-Geral e o Departamento de Estudos Econômicos (DEE).

O TADE é o órgão judicante, formado por um Presidente e seis Conselheiros, escolhidos dentre cidadãos com mais de 30 (trinta) anos de idade, de notório saber jurídico ou econômico e reputação ilibada, nomeados pelo Presidente da República, depois de aprovados pelo Senado Federal. Seus mandatos são de quatro anos, vedada a recondução. Conforme a referida lei, compete ao Plenário do TADE, por exemplo, decidir sobre a existência de infração à ordem econômica e aplicação de penalidades previstas em lei; decidir os processos administrativos destinados a imposição de sanções administrativas por infrações à ordem econômica instaurados pela Superintendência-Geral; aprovar os termos do compromisso de cessação de prática e do acordo em controle de concentrações, bem como determinar à Superintendência-Geral a fiscalização do seu cumprimento.

Ao seu turno, à Superintendência-Geral do CADE, composta por um SuperintendenteGeral e dois Superintendentes-Adjuntos, compete, por exemplo, monitorar o mercado ser o "cão de guarda da concorrência" -; conduzir procedimentos, inquéritos e $\mathrm{o}$ processo sancionador; conduzir procedimentos e processos de controle de concentrações; aprovar concentrações mais simples podendo impor medidas preventivas; propor termo de 
compromisso de cessação de prática por infração à ordem econômica, submetendo-o à aprovação do Tribunal, e fiscalizar o seu cumprimento e, por fim, celebrar acordo de leniência. 0 Superintendente-Geral será escolhido dentre cidadãos com mais de 30 (trinta) anos de idade, notório saber jurídico ou econômico e reputação ilibada, nomeado pelo Presidente da República, depois de aprovado pelo Senado Federal.

Quanto ao DEE, cuida-se de órgão é dirigido por um Economista-Chefe, com atribuição para elaborar estudos e pareceres econômicos, de ofício ou por solicitação do Plenário, do Presidente, do Conselheiro-Relator ou do Superintendente-Geral, zelando pelo rigor e atualização técnica e científica das decisões do órgão. O Economista-Chefe será nomeado, conjuntamente, pelo Superintendente-Geral e pelo Presidente do Tribunal, dentre brasileiros de ilibada reputação e notório conhecimento econômico. Após a nomeação, ele poderá participar das reuniões do Tribunal, sem direito a voto. Em essência, ao DEE cabe subsidiar tecnicamente a atuação do CADE.

Enfatiza-se que, a Lei Antitruste brasileira, para além de conferir mais autonomia ao CADE - ao atuar de forma preventiva e repressiva -, respectivamente, instituiu políticas públicas que buscam desestimular a prática de ilícitos ou que evitem prejuízos à livre concorrência, e aplicando sanções aos agentes econômicos. Ainda, cumpre informar que a Lei 12.529/2011 (BRASIL, 2011) observa um sistema de proteção dúplice da concorrência, de análise e o controle das estruturas e das condutas.

No que diz respeito ao exercício da competência repressiva da concorrência ilícita, é comum o surgimento de dificuldades de ordem prática, por exemplo, na obtenção de provas da prática anticoncorrencial, sobretudo nas hipóteses de ajustes entre agentes econômicos que atuam num mesmo mercado relevante (acordos horizontais), ou não (acordos verticais), e que tenham por objeto restringir ou eliminar a concorrência ou um concorrente, ou ainda aumentar arbitrariamente os lucros.

A dificuldade para a comprovação da ocorrência de tais práticas ilícitas e a necessidade de repressão e, mais do que isso, da cessação da infração, fez surgir instrumentos que se mostram efetivos na persecução administrativa, na repressão e punição: os acordos celebrados entre a Administração (CADE) e os agentes econômicos.

\section{CONTROLE DA ESTRUTURA E DAS CONDUTAS}

O controle dos atos de concentração econômica, ou controle de estruturas - atividade preventiva exercida pelo CADE - tem por objetivo examinar alterações provocadas por "movimentos empresariais nas estruturas dos mercados" (PEREIRA NETO; CASAGRANDE, 2016). Nessa seara, o CADE exerce a função de analisar os números de empresas ativas no mercado, a presença de barreiras que impedem a entrada de novos competidores, as características do produto comercializado etc. Tal ação de controle visa a coibir a criação de monopólios e oligopólios que propiciem preços que dificultem a competição no mercado, nos moldes da lei.

Nesse sentido, ao visualizarem operações empresariais que alterem ou tenham o condão de alterar as estruturas do mercado e, por corolário, a concorrência (GABAN; DOMINGUES, 2016), "as autoridades da concorrência fazem uma análise prospectiva" (PEREIRA NETO; CASAGRANDE, 2016) na busca de entrever se os movimentos estruturais das empresas poderão impactar de forma expressiva a sua conduta, de modo a afetar negativamente a atuação no mercado.

Ainda, no que tange aos atos de concentração, o principal dispositivo que versa sobre a matéria é o artigo 90 da Lei de Defesa da Concorrência, no 12.529/2011 (BRASIL, 2011), o qual delineia a existência de ato de concentração quando: - duas ou mais empresas se fundem, sendo anteriormente independentes (inciso I); uma ou mais empresas adquirem o controle ou partes de uma ou mais empresas, de forma direta ou indireta (inciso II); - uma ou mais empresas incorporam uma ou várias empresas (inciso III); ou - quando duas ou mais empresas assinam contrato associativo, consórcio ou joint venture (inciso IV).

Juridicamente as hipóteses acima mencionadas podem se materializar em diversas formas, conforme exemplificam Eduardo Molan Gaban e Juliana Oliveira Domingues (2016):

[...] essas operações podem se revestir das mais variadas formas e modalidades societárias, como fusões, incorporações, joint ventures, cisões, aquisições de participação acionária (minoritária e/ ou majoritária), consórcios, acordos de 
cooperação (para compra conjunta, venda conjunta, desenvolvimento de tecnologia, autorregulação250 etc.), industrialização por encomenda, alienação ou cessão de bens intangíveis como know-how, direitos de propriedade intelectual (como marca, desenho industrial e modelo de utilidade), lista de clientes, swap agreements etc. Podem, ainda, não possuir forma, mas realizar-se apenas no plano dos fatos, sendo igualmente suficientes a atrair a incidência da Lei Antitruste.

Ao olhar atentamente, vislumbra-se que a Lei de Defesa da Concorrência não destina uma forma ou modalidade específica para que se caracterize um ato de concentração econômica. Todavia, se o negócio que está sendo objeto de análise apresentar a possibilidade de modificar as relações da concorrência, o CADE destinará um olhar apurado para essa movimentação e verificará se trata, ou não, de concorrência ilícita.

No mais, a concorrência ilícita subdividese em duas espécies: a concorrência desleal e a infração à ordem econômica. A primeira configura-se quando o empresário, agindo isoladamente ou não, prejudica o interesse de outro agente econômico (seu concorrente), isto é, a conduta atua na esfera privada "do mercado" e a ilicitude fica alojada internamente, abrindo-se a possibilidade de repressão nas esferas cível e penal. Noutro giro, na infração da ordem econômica o comportamento anticoncorrencial ilícito, de um ou mais agentes econômicos, ganha outras proporções e prejudica o mercado. É o caso das operações empresariais que afetam de forma colossal o desempenho e as estruturas do mercado, fazendo com que a repressão estatal se dê nas ordens civil, penal e administrativa.

Nesta quadra, torna-se importante destacar a formação de cartel que, em consonância com a Lei no 8.137/90 (BRASIL, 1990), é crime contra a ordem econômica, dado que afeta a estrutura do mercado, sendo coibidos pelo CADE - através do controle preventivo - os atos de concentração com tendência ao conluio.
E é interessante destinar um olhar apurado sobre essa prática ilícita.

E é curioso notar que o número de notícias com o assunto "cartelização no Brasil" é crescente; nos últimos anos, esse aumento se deu, sobretudo, por conta da atuação mais efetiva do CADE, preventiva e repressivamente, viabilizada pela reformulação a atualização da legislação antitruste. Sem dúvida, a Lei 12.529/2011 (BRASIL, 2011), calcada na ordem que emana dos artigos 170 e 173, §4으, da Constituição Federal (BRASIL, 1988), para além de proteger a atividade econômica, a valorização do trabalho e da livre iniciativa, e reforçar as diretrizes basilares da economia de mercado brasileira atenta a justiça social igualitária prevista constitucionalmente (COELHO, 2017), potencializou a atuação da autarquia ao conferirIhe mais autonomia.

Segundo autorizada doutrina, "os cartéis são acordos entre concorrentes, atuais ou potenciais, destinados a arrefecer ou neutralizar a competição entre eles e que têm seu objeto ou efeito tipificado nos incisos do artigo 36, caput, da Lei no 12.529 de 2011" (FORGIONI, 2016). Ou seja, a formação de cartel - ou cartelização configura-se quando dois ou mais agentes econômicos, atuantes no mesmo ramo do mercado (colusão horizontal), operam em conjunto com a finalidade de aumentar seus ganhos e restringir ou eliminar a concorrência, através de movimentos ilícitos na estrutura do setor. Dessa maneira, os agentes infratores passam a fixar preços ou quotas de produção, combinar ofertas de produtos e a distribuição dos mesmos, bem como a divisão de clientes e de mercados de atuação.

Não se olvide, ainda, da possibilidade de caracterização da referida infração mesmo quando a colusão resulta de um acordo tácito (o paralelismo consciente $\left.{ }^{10}\right)$, resultando da mesma forma anticoncorrencial e condenável (COELHO, 2017)

É certo que a Lei Antitruste brasileira não traz em seu bojo a palavra "cartel", cuja definição obtém-se a partir das intervenções doutrinárias e da interpretação sistemática dada ao artigo 36 , §3ㅇ, do referido diploma legal. Aliás, é

\footnotetext{
${ }^{10}$ Também denominado paralelismo intencional, é considerado na definição descrita no inciso l, do §3으, do artigo 36, da Lei Concorrencial brasileira (n. 12.539/2011), a saber: “[...] § 3ㅇ As seguintes condutas, além de outras, na medida em que configurem hipótese prevista no caput deste artigo e seus incisos, caracterizam infração da ordem econômica: I - acordar, combinar, manipular ou ajustar com concorrente, sob qualquer forma: [...]." (Grifo nosso)
} 
interessante a constatação segundo a qual o legislador "delimitou a caracterização infracional do ato, não vedando o cartel per se" (DESCHK, 2016), já que as práticas proibidas são as hipóteses disciplinadas no mencionado dispositivo normativo e correspondem à infração de ordem econômica (FORGIONI, 2016).

Isso ocorre porque a lógica da Lei de Defesa da Concorrência trabalha com a construção de uma economia moderna e globalizada, para a qual exige-se constantemente a cooperação entre concorrentes, que, inclusive, pode ser benéfica aos consumidores dado o grau de interdependência de algumas unidades produtoras. Em outras palavras, alguns atos de concentração entre agentes econômicos considerados nocivos poderão ser autorizados pelo $\mathrm{CADE}^{11}$.

Retomando o estudo sobre o cartel, digase que a colusão, o ajuste, o conluio, afora ensejar a prática de infração administrativa, é conduta tipificada na Lei no 8.137/1990 (BRASIL, 1990), que define crimes contra a ordem tributária, econômica e contra demais relações de consumo. O que exige sejam feitos dois importantes apontamentos.

Primeiro, o artigo 4을 da respectiva lei, em seu inciso I, identifica as mesmas características da legislação administrativa, equivalendo-se às mesmas hipóteses delineadas no artigo 36 da Lei 12.529/2011 (BRASIL, 2011), acima enfrentadas. Em segundo lugar, diga-se que o inciso II, do art. 4으, da Lei no 8.137/1990 (BRASIL, 1990), veda expressamente o cartel per se, diferentemente do tratamento dado na esfera administrativa. Assim, nos casos em que acordos tenham por propósito fixar artificialmente preços de produtos ou serviços, controlar regionalmente o mercado econômico, ou controlar a rede de distribuição ou de fornecedores em prejuízo da concorrência, mesmo que independentemente de abuso de poder econômico ou de dominação do mercado, haverá configuração do ilícito e impor-se-á a respectiva penalidade (DESCHK, 2016).

\footnotetext{
${ }^{11}$ Dentro dessa perspectiva, a Lei no $12.529 / 2011$ (BRASIL, 2011) define os atos de concentração de empresa considerados infrações da ordem econômica (artigo 88 e $§ 5$ ㅇ), porém, ressalvando da reprovabilidade legal-concorrencial os chamados atos infracionais benéficos (artigo 88, §6), que restam autorizados pelo Poder Público porque praticados nos limites necessários ao alcance de determinados objetivos de interesse coletivo, a saber: aumento da produtividade ou da competitividade no mercado, melhoramento da qualidade de bens e serviços, obtenção de eficiência e desenvolvimento tecnológico ou econômico, e repasse dos benefícios aos consumidores.
}

Nesse cenário não há necessidade de comprovação de danos à concorrência com tais práticas. E é importante saber distinguir as infrações de ordem administrativa e penal. Veja bem, ao fazer essa distinção entre as legislações, que cuidam da formação de cartéis, dentre outras situações, pode ser avaliado em qual ramo do Direito se sujeita a violação legal.

Além disso, tal situação reverbera, por exemplo, no Direito Civil, ao passo que o Código (BRASIL, 2002) disciplina que quando o negócio jurídico tem por objeto algo ilícito - neste caso, as hipóteses constantes no inciso II, do art. 4으, da Lei no 8.137/1990 (BRASIL, 1990) - o mesmo será nulo (MAGGI, 2010). No mais, identificar as diferenças e demais implicações da cartelização auxilia na compreensão da celebração de acordos no âmbito da defesa da concorrência.

\section{CELEBRAÇÃO DE ACORDOS NO ÂMBITO DA DEFESA DA CONCORRÊNCIA: ACORDO DE LENIÊNCIA E TERMO DE COMPROMISSO DE CESSAÇÃO}

De início, ao dispensar um exame apurado do tema trazido à baila, é pertinente abordar as condições favoráveis para a cartelização. Paula Forgioni (2016), ao trazer os ensinamentos de Richard Allen Posner, apresenta alguns elementos que indicam uma propensão do mercado à formação de cartéis, a saber: pequeno número de agentes econômicos atuando no mercado, homogeneidade do produto, baixa elasticidade da demanda, existência de barreiras a entrada de novos competidores no mercado, retração e concentração elevada do mercado.

Dito isso, apesar da facilidade em visualizar a propensão do mercado à cartelização, provar a existência dessas infrações à ordem econômica é laborioso, "ainda mais se considerarmos que o comportamento paralelo pode decorrer das próprias características do mercado." (FORGIONI, 2016). Ademais, via de regra, a prática de cartel envolve um acordo não escrito entre agentes econômicos; ou seja, exige esforço para ser comprovada, tanto na esfera administrativa quanto na judicial e penal.

Nesse sentido, através da Lei Antitruste, no 12.529/2011 (BRASIL, 2011), a Administração Pública prevê três tipos de acordos que podem ser celebrados no sistema brasileiro concorrencial, na busca de contribuir com a investigação, são eles: Acordo de Leniência, Termo de Compromisso de Cessação e Acordo 
em Controle Concentrado. Porém, aqui serão explorados apenas os dois primeiros. Cabe frisar, os acordos têm por premissa facilitar a investigação para que haja o combate à prática de conluio.

Os órgãos antitrustes "têm se utilizado dos acordos de leniência como meio de verificação e obtenção de provas da formação de cartéis" (DESCHK, 2016, p. 10). Esse acordo tem por característica primordial incentivar um dos infratores a colaborar com as investigações e com o processo administrativo, de forma efetiva. Tal colaboração busca explorar e investigar a fundo as atividades ilícitas com a confissão de um dos participantes, que será responsável por identificar os agentes envolvidos na infração, além de contribuir na obtenção de informações e documentos, a fim de comprovar a infração noticiada ou sob investigação.

No Brasil, a leniência foi introduzida pela Lei no 10.149/2000 (BRASIL, 2000) e com o advento da Lei no 12.529/2011 (BRASIL, 2011) o instituto passou a ser chamado "Programa de Leniência", estando disciplinado nos artigos 86 e 87 deste diploma legal. A Lei Antitruste passou a prever que o CADE, por intermédio da sua Superintendência-Geral, realize acordos com um dos participantes da prática do cartel, o qual, ao confessar sua participação e entregar provas, poderá beneficiar-se com a extinção da ação punitiva da Administração Pública ou com a obtenção da redução da penalidade aplicável, de um terço a metade (FORGIONI, 2016).

Para a viabilização da realização do acordo de leniência devem ser observados alguns requisitos, elencados no referido artigo 86 da Lei no 12.529/2011 (BRASIL, 2011) e no artigo 197 do Regimento Interno do CADE - RICADE (BRASIL, 2019), a saber: o denunciante deverá ser o primeiro a se qualificar e se oferecer para delatar às autoridades o esquema infrator; ele deve fazer cessar a sua participação no conluio noticiado ou sob investigação; no momento em que há propositura do acordo, a Superintendência-Geral não deverá ter provas suficientes para condenar o proponente; além de confessar a sua participação no ilícito, o denunciante deve colaborar efetivamente para a obtenção de provas e identificação dos demais participantes e o denunciante deverá comparecer aos atos processuais, até o encerramento do processo, quando for solicitado (Regimento Interno do CADE, 2020).
No âmbito administrativo, a celebração do acordo, por pessoas físicas ou jurídicas autoras de infração à ordem econômica, poderá beneficiá-las com a extinção da ação punitiva ou a redução da penalidade aplicável, com fulcro no $\S 4$, art. 86 da Lei Antitruste. Em contrapartida, no âmbito criminal, os benefícios do acordo encontram-se elencados no art. 87 da mesma lei. É importante frisar, que os benefícios apenas serão concedidos com a declaração de cumprimento do acordo de leniência e, por corolário, quem o celebrou ganha imunidade administrativa e penal. Todavia, apesar dessas imunidades, o mesmo não ocorrerá na esfera civil, vez que 0 agente poderá ser responsabilizado pelos danos causados. Essa falta de imunidade civil é contraditória, explica-se:

$\mathrm{Na}$ seara de cartelização, as ações de responsabilidade civil têm um valor elevado na condenação e, sendo imprescindível, "a necessidade de confissão da conduta ilícita para a celebração do acordo aumenta a probabilidade de condenação na esfera cível" (DESCHK, 2016). Isso faz com que possíveis delatores não queiram fazer o acordo. Portanto, a confidencialidade de tal é importante para o curso das investigações.

Noutro giro, o Termo de Compromisso de Cessação antitruste (TCC), outro importante pilar da persecução pública dos cartéis no Brasil (ATHAYDE; FIDELIS, 2016), é um instrumento que permite aos demais infratores envolvidos no cartel, não habilitados para celebração do acordo de leniência, a alcançarem benefícios na seara administrativa, "mas sem benefícios automáticos na seara criminal" (ATHAYDE; FREITAS, 2021).

O TCC antitruste tem por objetivo compelir a conduta anticompetitiva, objeto da investigação, ou seus efeitos lesivos, estando disciplinado no artigo 85 da Lei no $12.529 / 11$ (BRASIL, 2011) e nos artigos 178 a 195 do RICADE (BRASIL, 2019). Aqui, não há detecção de condutas, como no acordo de leniência, pois há conhecimento prévio da infração ou a Superintendência-Geral, no momento da celebração, possui provas suficientes da conduta ilícita, que podem ter sido obtidas por meio de investigação ou porque exista um Acordo de Leniência celebrado anteriormente.

Assim como ocorre no Programa de Leniência, para que haja a celebração do TCC, "no âmbito de investigações de acordo, combinação, manipulação ou ajuste entre concorrentes" (ATHAYDE; FREITAS, 2021), são exigidos alguns requisitos: obrigação de cessar a prática da 
conduta objeto de investigação; pagamento de multa, caso o termo seja descumprido; colaboração com a instrução do processo; o infrator deve reconhecer a sua participação na cartelização e pagar contribuição pecuniária ao Fundo de Defesa dos Direitos Difusos. Diga-se, ainda, que a autoridade antitruste pode estipular outras condições específicas para que o termo se adeque ao caso concreto.

Registra-se, em consonância com o artigo 85, in fine, da Lei no 12.529/2011 (BRASIL, 2011), que mesmo atendendo-se aos requisitos supramencionados, a autoridade concorrencial poderá rejeitar a proposta de celebração do termo de compromisso de cessação, exatamente porque a celebração do TCC se insere na competência discricionária do Poder Público, que decide segundo critérios de conveniência e oportunidade.

A tais características e vicissitudes acrescenta-se que a expectativa relacionada aos efeitos do acordo de leniência, somada ao requisito da primazia, revela "uma espécie de 'corrida' entre os participantes da conduta anticompetitiva" e que "os TCCs podem ser celebrados depois de concluída a instrução do processo administrativo" (ATHAYDE; FREITAS, 2021, não paginado). Esta "corrida" entre os infratores se assenta no fato de que os melhores benefícios (maiores descontos na contribuição pecuniária) são conferidos ao agente econômico que primeiro se qualificar e se oferecer para delatar o esquema infrator às autoridades. Quanto ao TCC, lembra-se que não há a exigência da primazia para a sua celebração, estando aberto a todos os participantes da conduta investigada. Ante os benefícios carreados ao agente econômico infrator, o acordo de leniência se põe mais atrativo.

Ambos institutos contribuem para o combate à cartelização, auxiliando nas investigações, à medida que viabilizam a obtenção e a produção de provas sem as quais seria impossível comprovar a colusão e identificar os infratores.

A tendência ao aumento da celebração desses acordos foi bem delineada por Amanda Athayde e Sarah Roriz de Freitas (2021). Forte nas informações contidas na pesquisa de Fernando Martins Chíxaro (2020), as autoras constaram que, de 60 processos administrativos instaurados entre os anos de 2015 e 2019 visando a apuração da prática de cartelização, 36 decorreram de acordos de leniência (60\%). As pesquisas revelaram, ainda, que:

Assim, há indicativos de que: 1) os TCCs são mais presentes em processos originados por acordos de leniência do que por outros meios; e 2) entre os processos instaurados em decorrência de acordos de leniência, há mais casos com TCCs celebrados do que casos sem nenhum TCC. (ATHAYDE E FREITAS, 2021)

Nesse sentido, a título de ilustração serão apresentados, de forma sintetizada, dois casos concretos, em que o CADE atuou no combate a conluios.

O primeiro envolve uma formação de cartel internacional que operou, entre 1995 e 2007, para aumentar o preço de TVs analógicas no mundo inteiro, inclusive no Brasil (VENTURA, 2018). A investigação iniciou em 2008, quando a Samsung celebrou Acordo de Leniência com o CADE, confessando a sua participação no cartel e apresentando provas de como o conluio ocorria no Brasil. Além do Acordo, a empresa também assinou o Termo de Compromisso de Cessação. Nesse episódio, outras empresas envolvidas assinaram um TCC (LG, Philips, Technicolor, Chunghwa e LP Displays). E, em 2018, apenas a Toshiba foi condenada.

No segundo caso, o CADE condenou, no dia 30 de junho de 2021, cinco empresas e seis pessoas físicas por cartelização em licitações públicas para o fornecimento de tubos e conexões de PVC, que eram destinadas a obras de infraestrutura de saneamento, obras prediais e de construção civil (ALERIGI JUNIOR., 2021). Após instaurada a investigação pela autarquia (2016) realizou-se um acordo de leniência com uma das empresas envolvidas (Tigre S/A) e seus funcionários. Ao longo do processo administrativo, o CADE firmou quatro Termos de Compromisso de Cessação (BR Plásticos Indústria, BRP Indústria Plástica, Nicoll Indústria Plástica e Amanco Brasil) e as empresas que os celebraram pagaram cerca de 104,4 milhões de reais ao Fundo de Defesa de Direitos Difusos (ALERIGI JUNIOR, 2021). Ademais, foi apurado que dentre as condutas anticompetitivas praticadas, entre 2007 e 2014, estavam a fixação artificial de preços, divisão de lotes em licitações públicas e 
abstenção em certames. Em razão do acordo, os beneficiários da leniência tiveram a extinção da punibilidade administrativa e criminal (Consultor Jurídico, 2021, não paginado).

À vista disso, observa-se a inter-relação positiva entre ambos institutos na seara do direito concorrencial brasileiro. Isso ocorre, porque os Acordos de Leniência criam um terreno frutífero para a celebração dos Termos de Compromisso de Cessação. Portanto, é notório que essas ferramentas são fundamentais para uma efetiva e eficiente persecução dos ilícitos praticados contra a livre concorrência.

\section{CONCLUSÃO}

O direito da concorrência, para além de mero conjunto de normas e princípios concebidos para assegurar a liberdade econômica no mercado, evoluiu e, contemporaneamente, com a sua constitucionalização, tornou-se instrumento estatal importante para a repressão do abuso do poder econômico e para a tutelada livre concorrência, enquanto políticas públicas econômicas.

A criação de normas de combate às infrações no âmbito concorrencial foi oportuna, ao passo que associações com tendência ao conluio e de domínio do mercado desprestigiam princípios consagrados na Constituição Federal, a exemplo da livre iniciativa e dignidade da pessoa humana - importantes balizadores da ordem econômica -, ou seja, constrangem os ideais democráticos. Tendo o cartel como a prática anticompetitiva mais grave, por desregulamentar as estruturas e o desempenho do mercado, respectivamente, de forma interna e externa.

Por fim, importante ressaltar que, a lei brasileira de defesa da concorrência aperfeiçoou o sistema destinado à prevenção e repressão da concorrência ilícita, sobretudo conferindo ao CADE mais autonomia, se lhe permitindo - e impondo - segundo um sistema de proteção dúplice da concorrência - controle das estruturas e das condutas -, a celebração de acordos (compromissos de cessação e acordos de leniência) com agentes econômicos infratores, instrumentos que se revelam importantes e efetivos para a comprovação da ocorrência de práticas ilícitas, a sua punição e a prevenção, principalmente no que toca a formação de cartéis.

\section{REFERÊNCIAS}

ALERIGI JÚNIOR, Alberto. Cade condena 5 empresas e 6 pessoas por cartel de tubos e conexões de PVC. CNN Brasil. jun. 2021. Disponível em: https://www.cnnbrasil.com.br/business/2021/06 /30/cade-condena-5-empresas-e-6-pessoas-porcartel-de-tubos-e-conexoes-de-pvc. Acesso em: 11 jul. 2021.

ATHAYDE, Amanda; FIDELIS, Andressa. Discovery, Leniência, TCC e persecução privada a cartéis: too much of a good thing?. Revista do Ibrac, v. 22., p. 89-116, 2016.

ATHAYDE, Amanda; FREITAS, Sarah R. Pipoca com guaraná: combinando acordos de leniência com os do tipo second best. Consultor Jurídico, abr., $2021 . \quad$ Disponível em: https://www.conjur.com.br/2021-abr17/opiniao-combinando-acordos-lenienciasecond-best. Acesso em: 10 de jul. de 2021.

BAGNOLI, Vicente. Comentários à Nova Lei de Defesa da Concorrência. São Paulo: Ed. Revista dos Tribunais, 2017.

BRASIL. Presidência da República. Constituição da República Federativa do Brasil de 1988. Brasília, 5 de outubro de 1988. Disponível em: http://www.planalto.gov.br/ccivil_03/constituica o/constituicao.htm. Acesso em: 08 jul. 2021.

BRASIL. Presidência da Republica. Decreto no 9.745. Brasília, 8 de abril de 2019. Aprova a Estrutura Regimental e o Quadro Demonstrativo dos Cargos em Comissão e das Funções de Confiança do Ministério da Economia, remaneja cargos em comissão e funções de confiança, transforma cargos em comissão e funções de confiança e substitui cargos em comissão do Grupo-Direção e Assessoramento Superiores DAS por Funções Comissionadas do Poder Executivo - FCPE. Disponível em: http://www.planalto.gov.br/ccivil_03/_ato20192022/2019/decreto/D9745.htm. Acesso em: 08 de jul. de 2021.

BRASIL. Presidência da República. Lei no 8.137, de 27 de dezembro de 1990. Define crimes contra a ordem tributária, econômica e contra as relações de consumo, e dá outras providências. Diário Oficial da União, Brasília-DF, 28 de dezembro de $1990 . \quad$ Disponível em: 
http://www.planalto.gov.br/ccivil_03/leis/18137. htm. Acesso em: 08 jul. 2021.

BRASIL. Presidência da República. Lei no 10.149, 21 de dezembro de 2000. Altera e acrescenta dispositivos à Lei $n^{\circ} 8.884$, de 11 de junho de 1994, que transforma o Conselho Administrativo de Defesa Econômica - CADE em autarquia, dispõe sobre a prevenção e repressão às infrações contra a ordem econômica, e dá outras providências. Brasília, 21 de dezembro de 2000. Disponível

em: http://www.planalto.gov.br/ccivil_03/leis//10149 .htm. Acesso em: 08 jul. 2021.

BRASIL. Presidência da República. Lei no 10.406, de 10 de janeiro de 2002. Institui o Código Civil. Diário Oficial da União, Brasília-DF, 10 de janeiro de $2002 . \quad$ Disponível em: http://www.planalto.gov.br/ccivil_03/leis/2002/l 10406compilada.htm. Acesso em: 08 jul. 2021.

BRASIL. Presidência da República. Lei no 12.529, de 30 de novembro de 2011. Estrutura o Sistema Brasileiro de Defesa da Concorrência; dispõe sobre a prevenção e repressão às infrações contra a ordem econômica; altera a Lei no 8.137, de 27 de dezembro de 1990, o Decreto-Lei no 3.689, de 3 de outubro de 1941 - Código de Processo Penal, e a Lei no 7.347, de 24 de julho de 1985; revoga dispositivos da Lei no 8.884 , de 11 de junho de 1994, e a Lei no 9.781, de 19 de janeiro de 1999; e dá outras providências. Diário Oficial da União, Brasília-DF, 1 nov. 2011. Disponível em: http://www.planalto.gov.br/ccivil_03/_ato20112014/2011/lei/l12529.htm. Acesso em: 08 jul. 2021.

CADE. Conselho Administrativo de Defesa Econômica. Práticas Anticompetitivas: Cade condena cartel de fornecimento de tubos e conexões de PVC em licitações. Revista Consultor Jurídico, 30 jun. 2021. Disponível em: https://www.conjur.com.br/2021-jun-30/cadecondena-cartel-fornecimento-tubos-pvclicitacoes. Acesso: 11 jul. 2021.

CADE. Conselho Administrativo de Defesa Econômica. Regimento Interno do CADE. 2020. Disponível em: https://cdn.cade.gov.br/Portal/centrais-deconteudo/regimento-interno/Regimento-interno-
Cade-versao-05-2021.pdf. Acesso em: 10 jul. 2021.

CHÍXARO, Fernando Martins. Os Acordos depois do Acordo: Da comparação entre Termos de Cessação Conduta homologados no Cade em processo com e sem Acordos de Leniência, entre de 2015 a 2019. 2020. Monografia (Trabalho de Conclusão da Pós Graduação) - Fundação Getúlio Vargas, São Paulo, 2020.

COELHO, Fabio Ulhoa. Curso de Direito Comercial: direito de empresa. São Paulo: Editora Revista dos Tribunais, 2017. v.1.

COMPARATO, Fábio Konder. 0 indispensável direito econômico. Ensaios e pareceres de direito empresarial. São Paulo: Forense, 1978.

DESCHK, João Paulo Vieira. A formação de cartéis e a proposição de acordos de leniência por parte das empresas autoras de infração à ordem econômica. Revista Brasileira de Direito Empresarial. Curitiba, v. 2, n. 2, p. $177-197$, jul. /dez. 2016. https://doi.org/10.26668/IndexLawJournals/2526 $\underline{-0235 / 2016 . v 2 \mathrm{i} 2.1290}$

FORGIONI, Paula A. Os fundamentos do antitruste. 9. ed. São Paulo: Ed. Revista dos Tribunais, 2016.

FORGIONI, Paula. A evolução do direito comercial brasileiro: da mercancia ao mercado. São Paulo: Ed. Revista dos Tribunais, 2009.

FONSECA, João. Bosco Leopoldino da. Direito econômico. 9. ed. Rio de Janeiro: Forense, 2017.

FRAZÃO, Ana. Direito da concorrência: pressupostos e perspectivas. São Paulo: Saraiva, 2017.

GABAN, Eduardo Molan; DOMINGUES, Juliana Oliveira. Direito antitruste. 4. ed. São Paulo: Saraiva Jur, 2016.

GIL, Antonio Carlos. Métodos e técnicas de pesquisa social. 6.ed. São Paulo: Atlas, 2008.

MAGGI, Bruno Oliveira. 0 cartel e seus efeitos no âmbito da responsabilidade civil. 2010. $233 \mathrm{f}$. Dissertação (Mestrado em Direito) - Universidade de São Paulo, São Paulo, 2010. 
MINAYO, Maria Cecília de Souza (org.). Pesquisa social: teoria, método e criatividade. 29. ed. Petrópolis, RJ: Vozes, 2010.

PEREIRA NETO, Caio Mário da Silva ; CASAGRANDE, Paulo Leonardo. Direito concorrencial. São Paulo: Saraiva, 2016.

SALOMÃO FILHO, Calixto. Regulação da atividade econômica. São Paulo: Malheiros, 2008.

VENTURA, Felipe. Samsung, LG, Philips e Toshiba formaram cartel para aumentar preços de TVs. Tecnoblog. 23 ago. 2018. Disponível em: https://tecnoblog.net/257015/cade-cartel-tvcrt/. Acesso em: 11 de jul. de 2021. 